\title{
Efeitos da erosão e de técnica de manejo sobre a produção do algodoeiro ${ }^{1}$
}

\author{
Nilda B. de Lacerda² \& José R.C. Silva ${ }^{2}$
}

\begin{abstract}
RESUMO
Com este trabalho objetivou-se caracterizar os efeitos da erosão e da conservação do solo nas propriedades de um Luvissolo e avaliar o comportamento da rotação algodão/adubo verde com e sem inoculação de rizóbio na melhoria da produtividade do solo e do rendimento do algodoeiro. O experimento foi desenvolvido em casa de vegetação da UFC/CCA, utilizando-se cilindros de PVC com $11 \mathrm{~kg}$ de solo. Os tratamentos foram definidos como: camada ligeiramente erodida $(\mathrm{Cl}$ e $\mathrm{C}$ ) e camada severamente erodida (DI e D) cultivada com adubo verde com e sem inoculação de rizóbio. O delineamento experimental utilizado foi o inteiramente casualizado, com 6 repetições. Avaliaram-se: altura de plantas, número de maçãs por planta, matéria seca da parte aérea, massa de capulho por planta, número de sementes por planta, massa de sementes e nutrientes no solo, antes e após a aplicação do adubo verde. As melhores condições edáficas encontradas no solo conservado potencializaram os efeitos positivos do tratamento $\mathrm{Cl}$ com aumento significativo do rendimento do algodão; as condições no solo degradado foram melhoradas pela rotação feijão-de-porco/algodão e os rendimentos, do adubo verde ou do algodão em $\mathrm{DI}$, não atingiram aqueles obtidos em $\mathrm{C}$.
\end{abstract}

Palavras-chave: rotação de culturas, degradação do solo, inoculação com rizóbio

\section{Effect of erosion and management technique on the production of cotton}

\begin{abstract}
The objective of this work was to characterize erosion and soil conservation effect on properties of Luvissolo and to evaluate the behavior of cotton/green manure rotation with or without rhizobium inoculation in the improvement of soil productivity and cotton yield. The experiment was conducted in a greenhouse of UFC/CCA, using cylinders of PVC with $11 \mathrm{~kg}$ of soil. The treatments had been defined as: slightly eroded layer $(\mathrm{Cl}$ and $\mathrm{C}$ ) and severely eroded layer ( $\mathrm{DI}$ and $\mathrm{D}$ ) cultivated with green manure with and without rhizobium innoculation. The experimental design was completely randomized, with 6 replications. The height of plants, number of fruit per plant, dry matter of the aerial part, boll weight per plant, number of seeds per plant, weight of seeds and nutrient contents in the soil before and after the application of the green manure were evaluated. The best edaphic conditions found in the conserved soil potentialised the positive effect of treatment $\mathrm{Cl}$ with significant increase in cotton yield; the conditions in the degraded soil had been improved by the rotation beans cotton; the yields in both green manure and cotton in DI were lower than obtained in C.
\end{abstract}

Key words: crop rotation, soil degradation, rhizobium inoculation

1 Parte da Dissertação de Mestrado do primeiro autor

${ }^{2}$ Departamento de Ciências do Solo/UFC. DEP 60455-760, Fortaleza, CE. Fone: (85) 4008-9693, Fax: (85) 4008-9690. E-mail: lacerdanb@yahoo.com.br;jrcsilva@ufc.br 


\section{INTRODUÇÃO}

O solo, do tipo Luvissolo, abrange cerca de 2.699.320 ha e se situa em terceiro lugar, logo após os Podzólicos e os Litossolos, em termos de ocupação das terras do Ceará. Face às suas características de alta fertilidade natural, o Luvissolo vem sendo extensivamente utilizado com pecuária em regime de super-pastejo e culturas de ciclo curto, não obstante sua ocorrência em áreas onde predominam o clima semi-árido seco e a pedregosidade superficial, muito comuns nesses solos. Em áreas em que esta última limitação não chega a impedir totalmente a mecanização agrícola, esta vem sendo realizada de forma predatória, sem nenhuma preocupação conservacionista que possa minimizar a alta suscetibilidade à erosão que tal solo apresenta e, em conseqüência, vem sendo constatada sua crescente degradação; portanto, é freqüente, nesta situação, a ocorrência de perfís onde o horizonte B textural já aflora pela remoção completa do horizonte A pela erosão e, em conseqüência, a queda da produtividade do solo conduz a baixíssimos rendimentos do algodoeiro; desta forma, a geração de conhecimentos fundamentada na formação de uma base de dados sobre as mudanças impostas pela erosão nas características físicas e químicas desse solo, em comparação com as que ocorrem no perfil original em bom estado de conservação, é fundamental para o monitoramento do grau de recuperação passível de obtenção, através de práticas de uso, manejo e conservação.

Os métodos diretos e indiretos de avaliação dos efeitos da erosão sobre a produtividade apresentam algumas limitações, porém se reconhece que o melhor indicador da produtividade do solo é o rendimento da cultura nele utilizada (Pierce, 1991); além disso, a compreensão do relacionamento entre a qualidade do solo e a erosão é fundamental, tanto para a identificação e seleção de estratégias para um efetivo controle e prevenção do processo erosivo como para a recuperação da capacidade produtiva dos solos degradados e, neste sentido, Stewart et al. (1991), ao comentarem sobre a definição de uma agricultura sustentável, recomendam pesquisas sobre práticas de produção, utilizando-se a biotecnologia, destacando-se neste contexto a adubação verde, associada à inoculação com rizóbio, como uma das técnicas mais promissora para recuperação de solos degradados, a baixo custo.

Ante o exposto, conduziu-se o presente trabalho com o objetivo de caracterizar os efeitos da erosão e da conservação do solo nas propriedades de um Luvissolo e avaliar o comportamento da rotação algodão/adubo verde com e sem inoculação de rizóbio, na melhoria da produtividade do solo e do rendimento do algodoeiro.

\section{MATERIAL E MÉTODOS}

O presente trabalho foi conduzido em casa de vegetação do Departamento de Ciência do Solo do Centro de Ciências Agrárias, CCA, da Universidade Federal do Ceará (UFC), Campus do Pici, em Fortaleza, CE. Utilizaram-se substratos de um solo proveniente dos $20 \mathrm{~cm}$ superficiais do perfil de um Luvissolo, segundo classificação da Embrapa (1999), retira- dos de duas áreas encontradas naturalmente sob duas classes de erosão, na Fazenda São Vicente, no Município de Canindé, CE.

a) Erosão ligeira: determinada em uma área sob vegetação de pastagem natural sem utilização agrícola, correspondente ao solo conservado; nesta área, cerca de $10 \mathrm{~cm}$ do perfil pertenciam ao horizonte $\mathrm{A}_{3}$ e o restante ao horizonte $\mathrm{B}$.

b) Erosão forte: determinada na área do mesmo solo em que, face à ausência de qualquer técnica conservacionista e ao uso predatório em agricultura de subsistência, o solo já apresentava remoção do horizonte A e exposição do horizonte $\mathrm{B}$, correspondendo ao solo degradado.

Após a coleta dos substratos em cada classe de erosão, o solo foi encaminhado ao Laboratório do Departamento de Ciências do Solo/UFC e em seguida submetido às análises físicas e químicas, segundo metodologia descrita no manual de métodos e análise de solo (Embrapa, 1997). Segundo a análise granulométrica, o solo foi classificado como francoarenoso e os tratamentos definidos pelas duas classes de erosão citadas, caracterizando o solo conservado (C) e o degradado (D) além de dois tratamentos referentes à inoculação, ou seja, com e sem inoculação (CI e DI). Adotou-se o delineamento experimental inteiramente casualizado, com os tratamentos distribuídos em esquema fatorial $2 \times 2$ (classes de erosão x inoculação) com 6 repetições, totalizando 24 cilindros. A unidade experimental foi representada por cilindros de PVC com $53 \mathrm{~cm}$ de altura e 28,4 cm de diâmetro, contendo $11 \mathrm{~kg}$ de terra fina seca ao ar (TFSA); para isto, as amostras foram acondicionadas, replicando-se as densidades através da acomodação da mesma massa de solo em volumes compatíveis com os valores originais da densidade de 1,39 e de 1,54 $\mathrm{kg} \mathrm{dm}^{-3}$ para os solos conservado e degradado, respectivamente.

Utilizou-se uma rotação do algodoeiro herbáceo (Gossypium hirsutum L.r. latifolium Hutch ), cultivar CNPA 7H, procedente do Centro Nacional de Pesquisa de Algodão- CNPA, como cultura teste para avaliar o efeito dos tratamentos em sucessão ao feijão-de-porco (Canavalia ensiformes); esta leguminosa foi usada antes do plantio do algodão, no sentido de avaliar seus efeitos na melhoria da qualidade do solo, em ambas as classes de erosão em estudo.

Na primeira fase do experimento plantou-se feijão-de-porco, de acordo com os seguintes tratamentos:

1) Feijão-de-porco em solo conservado com inoculação (CI)

2) Feijão-de-porco em solo conservado sem inoculação (C)

3) Feijão-de-porco em solo degradado com inoculação (DI)

4) Feijão-de-porco em solo degradado sem inoculação

Como inoculante nas sementes foi utilizado o rizóbio (F2 + B2 + C2), oriundo do Centro Nacional de Pesquisa de Agrobiologia, da EMBRAPA-RJ e, para o plantio, utilizou-se 5 sementes por cilindro. Por ocasião da colheita determinaramse biomassa fresca, número de vagens por planta, grãos por vagem e rendimento da cultura caracterizada por produção de grãos (g por planta).

Em seguida, fez-se a semeadura do algodão, seguindo-se o esquema: 
1) Algodão em solo conservado após feijão-de-porco sem inoculação (C)

2) Algodão em solo degradado após feijão-de-porco sem inoculação (D)

3) Algodão em solo conservado após feijão-de-porco com inoculação (CI)

4) Algodão em solo degradado após feijão-de-porco com inoculação (DI)

A semeadura foi realizada colocando-se 5 sementes em cada cilindro; 8 dias após a emergência, realizou-se o desbaste, deixando-se uma planta por cilindro; durante todo o ciclo da cultura foi feita irrigação com $1000 \mathrm{~mL}$ de água destilada, três vezes por semana. No final do ciclo da cultura as plantas foram colhidas e computados os dados de altura de planta, matéria seca, número de maçãs, massa de capulhos e massa e número de sementes.

Após a colheita do algodão o solo passou por um período de pousio para, em seguida, ser plantado novamente o feijão-de-porco, desta vez sem inoculação e, portanto, só com o efeito residual do inoculante no feijão anterior, que foi colhido aos 58 dias após o plantio, correspondendo ao início da floração; depois do corte, as plantas foram colocadas para secar em estufa a temperatura de $65-70{ }^{\circ} \mathrm{C}$, até massa constante. A matéria seca obtida, cuja massa variou de 7,0 a 15,8 $\mathrm{g}$ em função da produção afetada pelos quatro citados tratamentos, foi adicionada à superfície do solo e incubada durante 40 dias, período em que foi adicionado $1 \mathrm{~L}$ de água destilada, duas vezes por semana.

Ressalta-se que o solo não passou por qualquer adubação química, seja corretiva ou de recuperação. Realizaram-se análises do solo com a finalidade de observar os benefícios da rotação de cultura com o feijão-de-porco e da adubação verde nas características do solo. Essas análises foram feitas: a) no início do experimento; b) antes da incubação do adubo verde e c) após incubação do adubo verde, totalizando três análises de solo, no decorrer do experimento.

Os resultados das variáveis determinadas foram submetidos a análise de variância e o nível de significância analisado através do teste "F". As médias foram comparadas entre si pelo teste de Tukey, a 5\% de probabilidade. Utilizou-se o programa estatístico Minitab (Ryan et al., 1985).

\section{RESULTADOS E DISCUSSÃO}

\section{Caracterização do solo em relação às classes de erosão}

Encontram-se, na Tabela 1, as características físicas e químicas do solo em estudo, nas duas classes de erosão, evidenciando aumento significativo do teor de argila na área degradada, em função da exposição do B textural; este aumento proporcionou elevação $(16,7 \%)$ no teor de água disponível, porém sem diferença significativa em relação ao solo conservado.

No solo conservado, o notável aumento de 53,7\% no teor de matéria orgânica influenciou significativamente a densidade global, a qual diminuiu em 9,7\% conduzindo, em consequência, a um aumento de $12,2 \%$ para a porosidade, em relação aos
Tabela 1. Características físicas e químicas da camada arável $(0-20 \mathrm{~cm})$ do solo Luvissolo, determinadas nas áreas com solo conservado e solo degradado pela erosão, antes do início do experimento

\begin{tabular}{lrrr}
\hline \multicolumn{1}{c}{ Características } & $\begin{array}{c}\text { Solo } \\
\text { Degradado }\end{array}$ & $\begin{array}{c}\text { Solo } \\
\text { Conservado }\end{array}$ & DMS $^{1}$ \\
Areia $(2-0,05 \mathrm{~mm}) \mathrm{g} \mathrm{kg}^{-1}$ & $610 \mathrm{a}$ & $700 \mathrm{~b}$ & 43 \\
Silte $\left(0,05-0,002 \mathrm{~mm} \mathrm{~g} \mathrm{~kg}^{-1}\right.$ & $240 \mathrm{a}$ & $220 \mathrm{a}$ & 61 \\
\hline Argila $(<0,002 \mathrm{~mm}) \mathrm{g} \mathrm{kg}^{-1}$ & $150 \mathrm{a}$ & $80 \mathrm{~b}$ & 43 \\
Densidade global, $\mathrm{kg} \mathrm{dm}^{-3}$ & $1,54 \mathrm{a}$ & $1,39 \mathrm{~b}$ & 0,08 \\
Porosidade, ${ }^{3} \mathrm{~m}^{-3}$ & $0,41 \mathrm{a}$ & $0,46 \mathrm{a}$ & 0,08 \\
Água disponível, $\mathrm{kg} \mathrm{kg}^{-1}$ & $0,07 \mathrm{a}$ & $0,06 \mathrm{a}$ & 0,02 \\
Matéria orgânica, $\mathrm{g} \mathrm{kg}^{-1}$ & $6,7 \mathrm{a}$ & $10,3 \mathrm{a}$ & 0,86 \\
Nitrogênio total, $\mathrm{g} \mathrm{kg}^{-1}$ & $0,3 \mathrm{a}$ & $0,4 \mathrm{a}$ & 0,0 \\
Fósforo, $\mathrm{mg} \mathrm{kg}^{-1}$ & $1,0 \mathrm{a}$ & $12,0 \mathrm{~b}$ & 0,64 \\
Cálcio, cmol $\mathrm{kg}^{-1}$ & $4,8 \mathrm{a}$ & $5,2 \mathrm{a}$ & 2,16 \\
Magnésio, $\mathrm{cmol}_{\mathrm{c}} \mathrm{kg}^{-1}$ & $2,5 \mathrm{a}$ & $4,9 \mathrm{a}$ & 4,57 \\
Potássio, $\mathrm{cmol}_{\mathrm{c}} \mathrm{kg}^{-1}$ & $0,2 \mathrm{a}$ & $0,4 \mathrm{~b}$ & 0,02 \\
Condutividade elétrica, dS m-1 & $0,62 \mathrm{a}$ & $0,24 \mathrm{~b}$ & 0,02 \\
\hline
\end{tabular}

${ }^{1}$ DMS: Diferença mínima significativa $(0,05)$.

Médias seguidas das mesmas letras nas linhas não diferem entre si pelo teste de Tukey, a 5 \% de probabilidade

valores encontrados para o solo degradado. Os bons atributos da matéria orgânica foram, portanto, responsáveis pela melhor qualidade física do solo conservado em relação ao degradado; além disso, por se tratar de fonte importante de $\mathrm{N}, \mathrm{P}$ e S e face à sua alta CTC, este componente orgânico do solo proporcionou, no solo conservado, melhores condições químicas, concordando com Kiehl (1985), quando este afirma que a matéria orgânica exerce efeitos positivos nas propriedades físicas, químicas e biológicas do solo; desta forma, ao se comparar os teores de nutrientes detectado no solo conservado e degradado evidenciou-se, neste último, reduções de nitrogênio (25\%), do cálcio $(8,7 \%)$, do magnésio (49\%), do fósforo $(91,3 \%)$ e do potássio $(48,9 \%)$ encontrando-se, nos dois últimos, diferenças estatisticamente significativas, como significativas também foram a diminuição da condutividade elétrica $(61,3 \%)$ verificados no solo conservado em relação ao solo degradado. Essas melhores condições edáficas relacionadas ao aumento dos teores de nutrientes, à ocorrência do $\mathrm{pH}$ numa faixa ótima para a nutrição vegetal e ao menor risco de salinidade, evidenciam o contraste entre os aumentos da fertilidade e o potencial de produtividade encontrados no solo conservado, ao empobrecimento e crescentes riscos de declínio da capacidade de suporte e ao desenvolvimento vegetal que a erosão provocou no solo degradado. Um prérequisito para predizer os impactos da erosão sobre a produtividade do solo, é a compreensão da natureza da relação entre esses dois parâmetros (Pierce, 1991).

\section{Produtividade do solo cultivado com feijão-de-porco inoculado com rizóbios na primeira etapa da rotação de culturas}

A má qualidade do solo degradado pela erosão, caracterizada pelas insatisfatórias condições físicas e químicas no tratamento D (Tabela 1) influenciou negativamente o rendimento das plantas em relação ao $\mathrm{C}$, detectando-se diminuições altamente significativas de $59,92,88$ e $97 \%$ para a biomassa 
fresca, número de vagens por planta, número de grãos por vagem e produção de grãos por planta (Figura 1), respectivamente; os dados aqui obtidos estão de acordo com a afirmação de Pierce (1991), quando afirma que o rendimento das culturas é o principal indicador dos efeitos da degradação do solo.

No solo conservado a inoculação com rizóbios (CI) promoveu ligeiros aumentos na biomassa (13\%) e produção de grãos $(11 \%)$ em relação ao tratamento C. O efeito benéfico da inoculação foi, porém, significativo na produtividade do solo degradado, posto que se verificam, em DI, aumentos de 400, 140 e $120 \%$ para vagens por planta, grãos por vagem e produção de grãos, respectivamente, quando comparado com o tratamento D; entretanto, o grau de degradação da qualidade do solo erodido, mesmo com a recuperação de parte de sua produtividade através da inoculação, não permitiu que o tratamento DI sequer se aproximasse do rendimento do solo conservado em $\mathrm{C}$, fato claramente evidenciado na Figura 1 ao se observar que o rendimento em grãos de feijão-de-porco por planta foi 10 vezes maior no tratamento $\mathrm{C}$ em relação ao DI.

Produtividade do solo cultivado com algodão em seqüência ao feijão-de-porco na primeira etapa da rotação de culturas

Para altura de plantas (Figura 2A) vê-se que, praticamente, não ocorreu diferença entre os tratamentos na mesma condição de solo porém, quando se comparam as duas condições, notou-se que o solo degradado foi o responsável pelos menores valores desta variável e, ainda, que os tratamentos CI e C foram superiores em 36,1 e 32,3\% em relação a DI e D, respectivamente.

Quanto à variável número de maçãs tem-se, na Figura 2B, que o tratamento $\mathrm{CI}$ continuou superando os demais tratamentos não existindo praticamente, diferença entre as condições de solo conservada e degradada. Observa-se que o responsável pelo menor número de maçãs foi o tratamento DI, enquanto o tratamento CI, que foi o responsável pelos maiores valores, superou o DI em 73,7\%.

$\mathrm{Na}$ Figura $2 \mathrm{C}$ vê-se que a matéria seca mostra a mesma tendência do ocorrido com o número de maçãs, ou seja, o CI respondeu pela maior produção de matéria seca e o DI pela menor produção. Para esta variável constata-se maior diferença quando se comparam os tratamentos entre as condições de solo degradado e o conservado. O tratamento CI superou o DI em $70,5 \%$.

Nas Figuras 2D, 2E e 2F, o tratamento CI foi o responsável pelo maior aumento na massa de capulho, número e massa de sementes apresentando, inclusive, maior destaque que nas variáveis anteriores. Da mesma forma como ocorreu nas outras variáveis analisadas, o tratamento DI respondeu pelo menor valor, enquanto o tratamento CI superou o DI em $80,2 \%$ na massa de capulho e número de sementes e em 79,5\% na massa de sementes. A superioridade dos tratamentos CI e C em relação a DI e D, é uma conseqüência das melhores condições físicas e químicas do solo conservado (Tabela 2).
A.

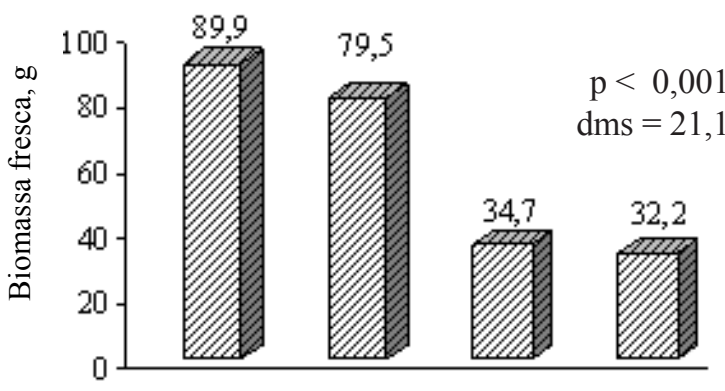

B.

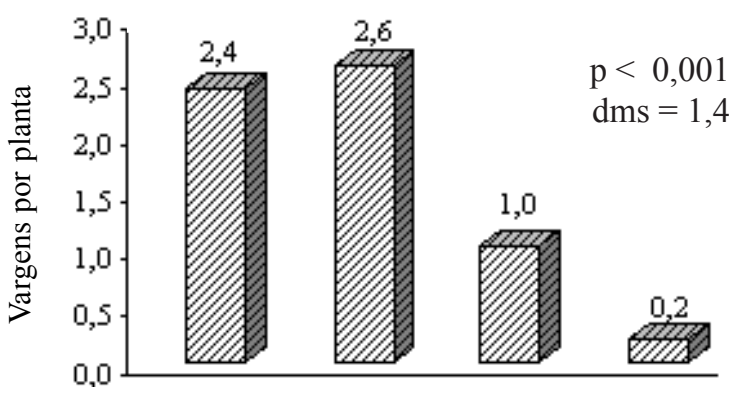

C.

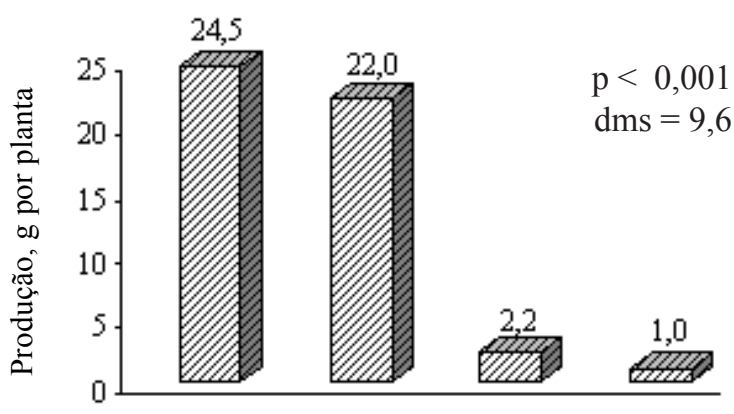

D.

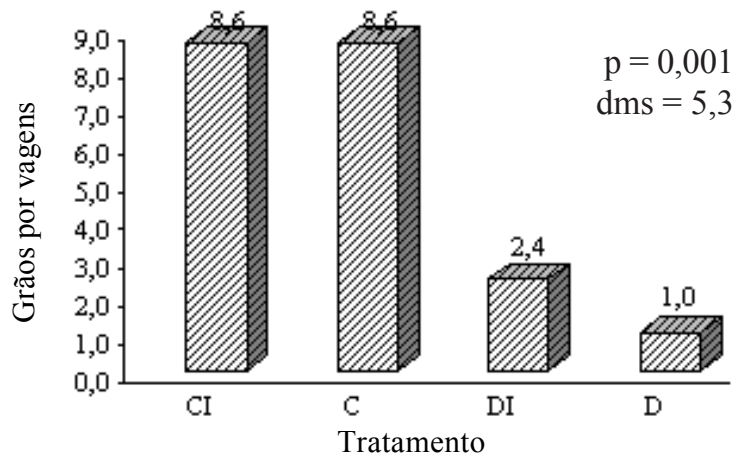

Figura 1. Biomassa fresca (A), vagens por planta (B), produção de grãos por planta (C) e grãos por vagem (D) de feijão-de-porco em um Luvissolo em condições conservada com inoculação $(\mathrm{Cl})$, sem inoculação $(\mathrm{C})$, degradada com inoculação (DI) e sem inoculação (D)

Rendimento do feijão-de-porco para adubação verde em seqüência ao algodão na segunda etapa da rotação de cultura

Encontram-se, na Figura 3, a biomassa fresca e a matéria seca de feijão-de-porco no solo em estudo, aos 58 dias após o plantio.

Como ocorreu com o feijão-de-porco da primeira etapa, o tratamento D permaneceu influenciando negativamente o rendimento das plantas em relação ao $\mathrm{C}$, que sofreu redução de $20 \%$ para biomassa fresca e matéria seca, embora só tenha 
A.

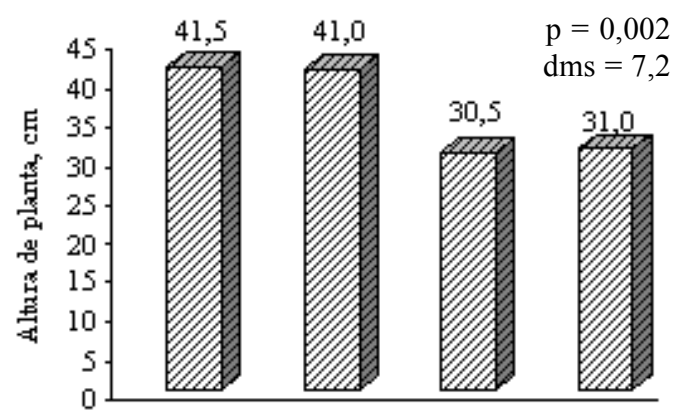

B.

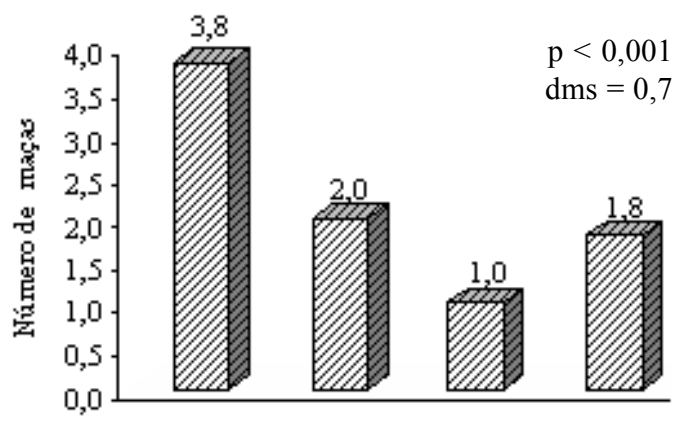

C.

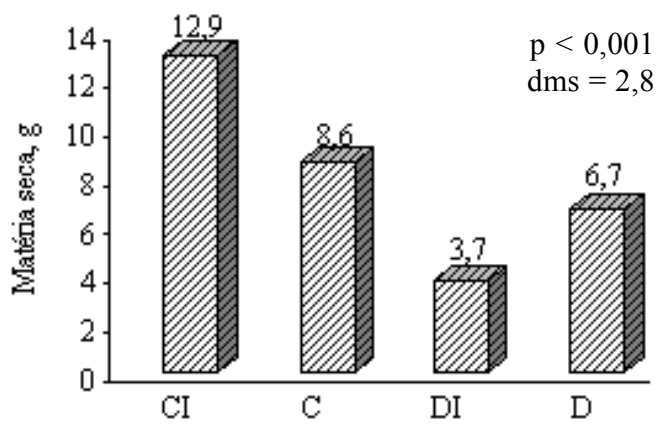

Tratamentos
D.

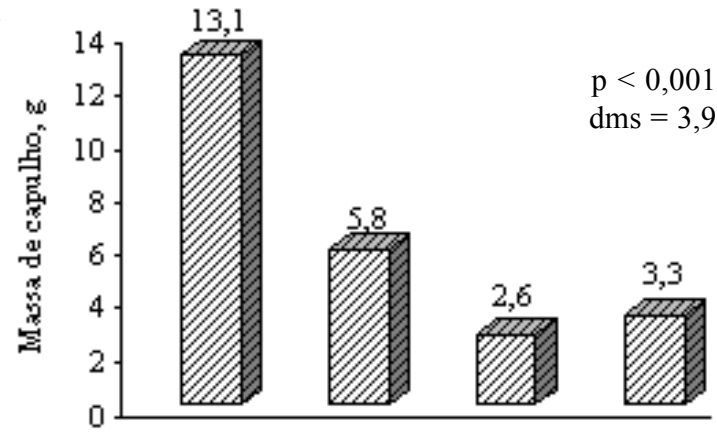

E.

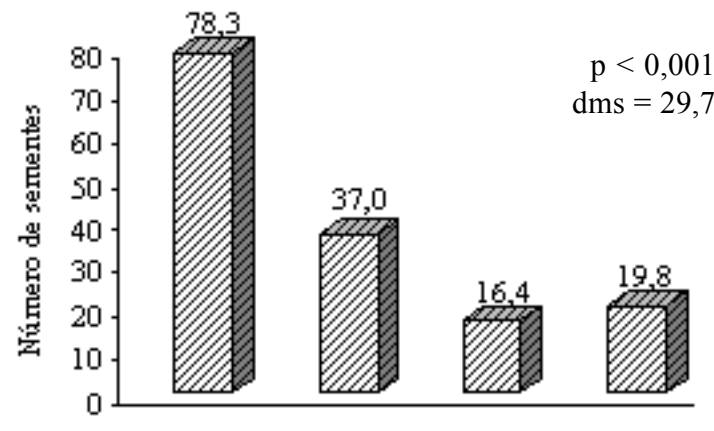

F.

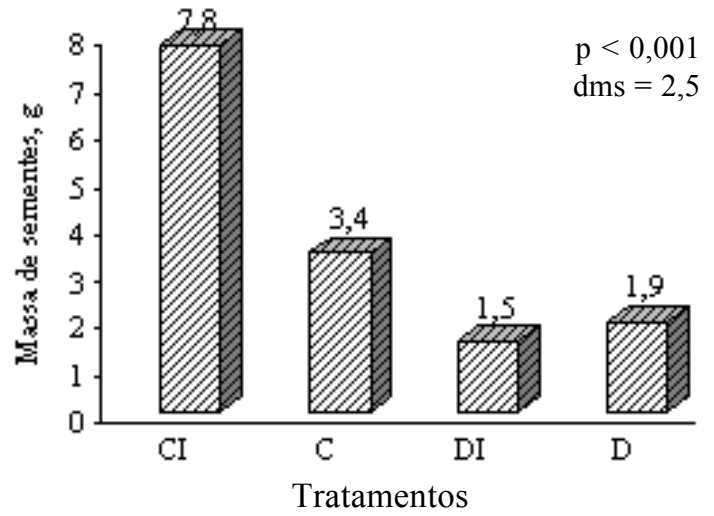

Figura 2. Altura de planta (A), número de maçãs (B), matéria seca (C), massa de capulho (D), número de sementes (E) e massa de sementes (F), de algodão em um Luvissolo em condições conservada com inoculação (Cl), sem inoculação (C), degradada com inoculação (DI) e sem inoculação (D) aos 138 dias após o plantio

ocorrido diferença significativa entre os tratamentos para a variável biomassa fresca. Os dados estão coerentes com os resultados da análise de solo realizada após a colheita do feijão-de-porco, (Tabela 2), na qual se observa que os teores de $\mathrm{N}, \mathrm{P}, \mathrm{K}, \mathrm{Mg}$ e matéria orgânica se apresentaram sempre superiores em $\mathrm{C}$, quando comparados com os de $\mathrm{D}$ e, ainda, que a rotação de cultura proporcionou maiores valores de biomassa fresca no solo degradado quando comparados com a biomassa fresca no referido solo, na primeira etapa (Figura 1), o que confirma as informações de Teixeira et al. (2003), ao afirmarem que a utilização de espécies com diferentes características de sistema radicular, que podem ser incluídas em sistemas de rotação e/ou de sucessão, é de extrema importância para o planejamento da recuperação de áreas fisicamente degradadas. Muitas vezes, a consorciação de duas ou mais espécies ou mesmo uma rotação adequada de culturas, é capaz de melhorar as características físicas de solos degradados.
Tabela 2. Características químicas ${ }^{1}$ de um Luvissolo determinadas após a colheita do feijão-de-porco nos tratamentos solo conservado (C), solo conservado com inoculação $(\mathrm{Cl})$, solo degradado (D) e solo degradado com inoculação (DI)

\begin{tabular}{|c|c|c|c|c|}
\hline Características & C & $\mathrm{Cl}$ & $\bar{D}$ & DI \\
\hline Nitrogênio total, $\mathrm{g} \mathrm{kg}^{-1}$ & $0,7 a$ & $0,7 \mathrm{a}$ & $0,4 \mathrm{C}$ & $0,6 \mathrm{~b}$ \\
\hline Fósforo, $\mathrm{mg} \mathrm{kg}^{-1}$ & $12,7 a$ & $14,7 a$ & $1,6 b$ & $1,3 b$ \\
\hline Potássio, $\mathrm{cmol}_{\mathrm{c}} \mathrm{kg}^{-1}$ & $0,6 a$ & $0,4 a$ & $0,4 a$ & $0,5 a$ \\
\hline Cálcio, $\mathrm{cmol}_{\mathrm{c}} \mathrm{kg}^{-1}$ & $8,2 \mathrm{a}$ & $7,5 a$ & $9,6 \mathrm{a}$ & $10,0 \mathrm{a}$ \\
\hline Magnésio, $\mathrm{cmol}_{\mathrm{c}} \mathrm{kg}^{-1}$ & $2,1 \mathrm{a}$ & $1,4 a$ & $1,8 \mathrm{a}$ & $2,0 \mathrm{a}$ \\
\hline Matéria orgânica, $\mathrm{g} \mathrm{kg}^{-1}$ & $12,4 a$ & $12,5 \mathrm{a}$ & $7,6 b$ & $9,9 b$ \\
\hline
\end{tabular}

Como nesta etapa o feijão-de-porco não foi inoculado e, sim, plantado em seqüência ao algodão, praticamente não ocorreram diferenças do solo conservado com inoculação com rizóbios $(\mathrm{CI})$ em relação ao tratamento $\mathrm{C}$, como na etapa 
A.

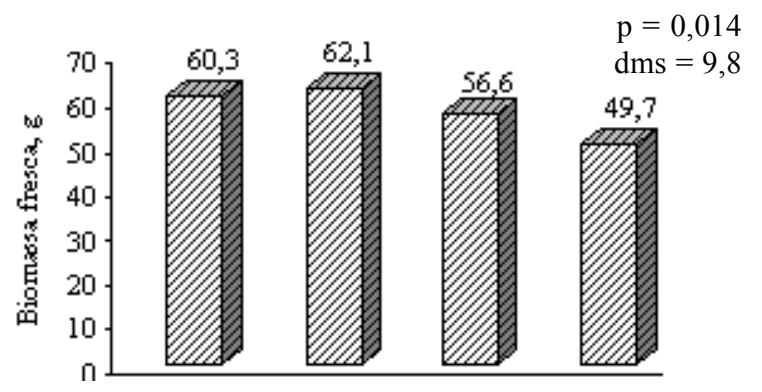

B.

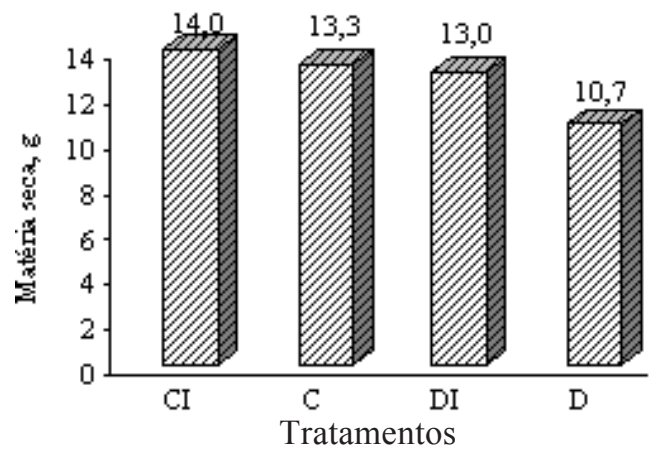

ns

Figura 3. Biomassa fresca (A) e matéria seca (B), de feijão-de-porco em um Luvissolo em condições conservada com inoculação $(\mathrm{Cl})$, sem inoculação $(\mathrm{C})$, degradada com inoculação (DI) e sem inoculação (D)

anterior, constatando-se apenas um pequeno aumento para a variável matéria seca; este fato se deve ao solo conservado já apresentar e manter elevados teores de nutrientes e boas propriedades físicas capazes de suprir as necessidades das plantas (Tabela 2).

Detectou-se, no solo degradado, a mesma tendência do feijão-de-porco anterior, ou seja, verificam-se em DI pequenos aumentos de 12 e $18 \%$ para biomassa fresca e matéria seca, respectivamente, quando comparado com o tratamento $\mathrm{D}$, embora não tenha ocorrido diferença significativa entre os tratamentos. Como em CI e C, os valores de N, K, Ca, Mg e matéria orgânica em DI foram ligeiramente superiores aos encontrados em $\mathrm{D}$ enquanto para o $\mathrm{P}$ os teores encontrados em $\mathrm{D}$ foram ligeiramente superiores, o que pode ser conseqüência do efeito residual da inoculação, visto que os dados aqui obtidos vêm confirmar as informações de Stewart et al. (1991), quando estes apontam técnicas agrobiológicas como alternativas para uma agricultura sustentável, entre as quais a utilização de leguminosas inoculadas com rizóbio.

Nota-se ainda, que, ao contrário do verificado no início do experimento (Figura 1), as diferenças entre os tratamentos DI e D em relação a CI e C, não foram acentuadas; além disso, nesta segunda etapa da rotação é notória uma aproximação nos valores de rendimento entre esses tratamentos nos solos conservado e degradado, não obstante haver permanecido a superioridade do primeiro (Figura 3); confirmou-se, portanto, o efeito benéfico da rotação e da inoculação de rizóbios no sentido de proporcionar melhoria na qualidade do solo degradado (Tabelas 2) e, em conseqüência, o maior rendimento das plantas nele cultivado; esses resultados estão coerentes com os obtidos por Merten \& Mielniczuk (1991) e Santos \&
Siqueira (1996), os quais verificaram que, do ponto de vista do manejo da fertilidade do solo, a rotação de culturas oferece a vantagem de, com o emprego de plantas de raízes fasciculadas, seguidas de plantas de raízes pivotantes e profundas, promoverem uma reciclagem dos nutrientes para a camada arável do solo; além disso, a rotação favorece características físicas como agregação, estrutura, drenagem e aeração e culturas menos exigentes em nutrientes poderiam aproveitar o efeito residual de adubos das culturas anteriores. O emprego de leguminosas, como no caso presente, também favorece a incorporação de nitrogênio ao solo, por meio da atividade simbiótica e a incorporação dos restos da cultura anterior preservaria o teor de matéria orgânica do solo.

\section{Efeito da adubação verde nas características químicas do solo}

A incubação do feijão-de-porco a partir daqui denominado adubo verde, à superfície do solo, proporcionou efeitos benéficos no que se refere à melhoria de sua fertilidade, tendo em vista aumentos de N, P, K, matéria orgânica e diminuição do $\mathrm{pH}$, tanto no solo conservado quanto no degradado (Figura 4).

Observa-se, na Figura 4, que os teores de nitrogênio, fósforo e potássio, presentes no solo após o corte do feijão de porco, aumentaram em relação aos seus valores iniciais detectados em C e D (Tabela 1).

Após a incubação do adubo verde os efeitos sobre a fertilidade do solo ainda foram mais pronunciados. Para o nitrogênio verificou-se aumento de 42,9, 14,3, 100 e 16,7\% para C, CI, D e DI, respectivamente.

O fósforo apresentou comportamento semelhante ao nitrogênio, ou seja, a incubação aumentou 41,7, 24,5, 94,1 e 184,6\% para C, CI, D e DI, respectivamente; entretanto, o tratamento DI foi o que proporcionou o maior aumento deste elemento, ao contrário do $\mathrm{N}$, em que o tratamento $\mathrm{D}$ foi o responsável pelo maior incremento.

Para o potássio tem-se a mesma tendência do $\mathrm{N}$ e P. De todos os nutrientes, o potássio foi o mais beneficiado com a prática da incubação, ocorrendo aumento de 100, 150, 250 e $200 \%$ para C, CI, D e DI, respectivamente. Nota-se que, para este elemento, os maiores aumentos ocorreram nos tratamentos D e DI. Os valores determinados no solo estão de acordo com os teores deste elemento, encontrados na matéria seca do feijão-de-porco (Kiehl, 1985).

Exceto para o tratamento D, os teores de magnésio apresentaram comportamento diferente dos demais nutrientes, posto que diminuiu após a incubação. Provavelmente por influência dos teores de potássio, sabe-se que teores muito altos de potássio podem agravar deficiência de magnésio (van Raij, 1981).

Para a matéria orgânica observa-se comportamento idêntico ao nitrogênio, onde incubação proporcionou aumentos de 40,3, 10,4, 63,2 e 18,2\% para C, CI, D e DI, respectivamente. Verificou-se, assim, a importância da rotação e utilização correta dos restolhos à superfície, como no sistema de plantio direto, no sentido de recuperar os baixíssimos níveis de ma- 
A.

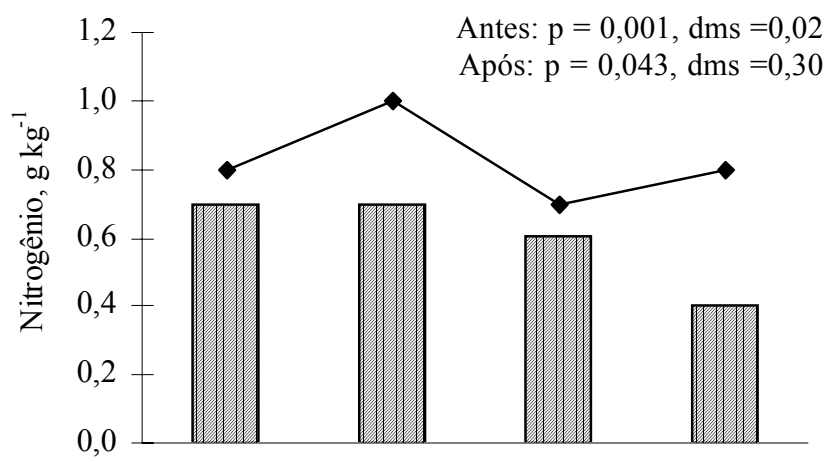

B.

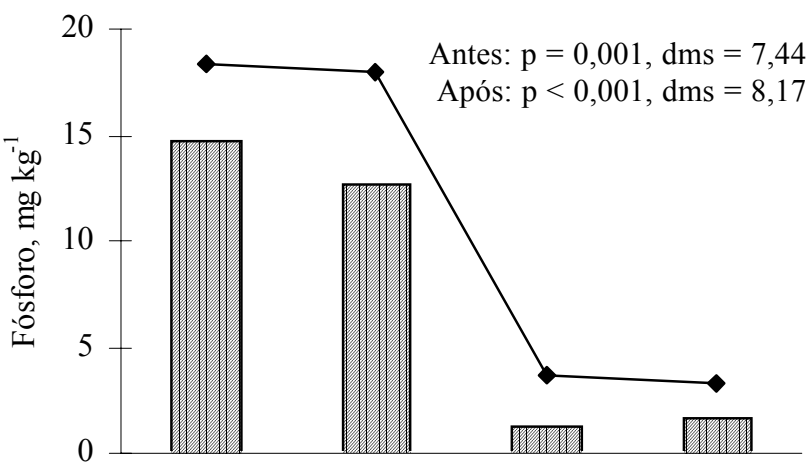

C.

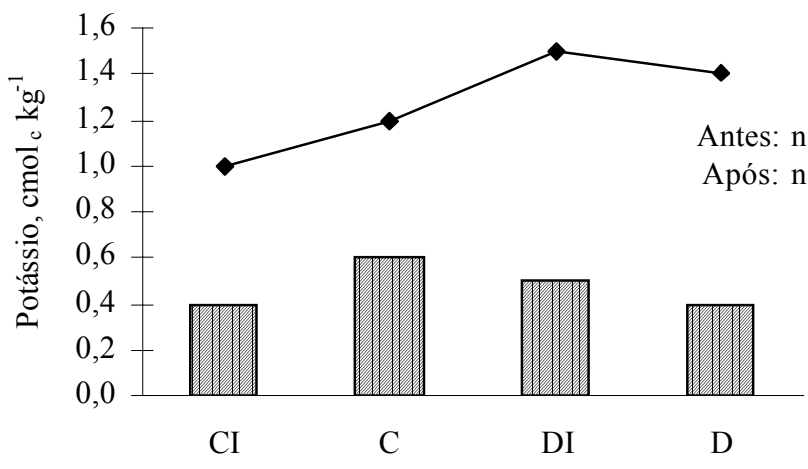

D.

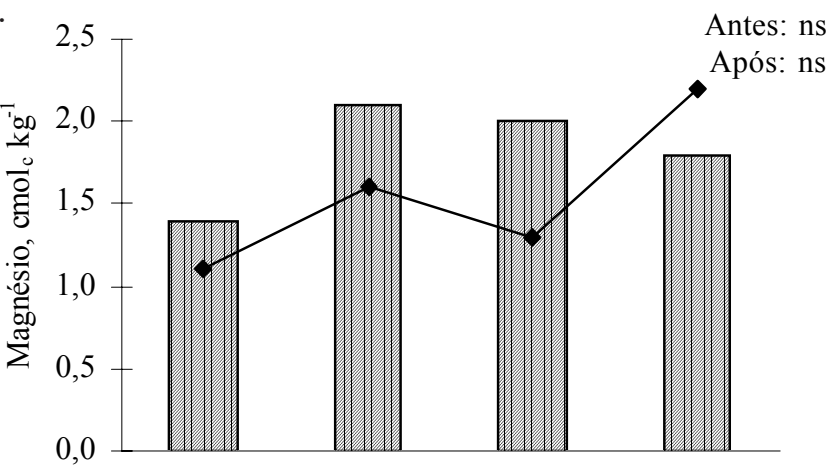

E.

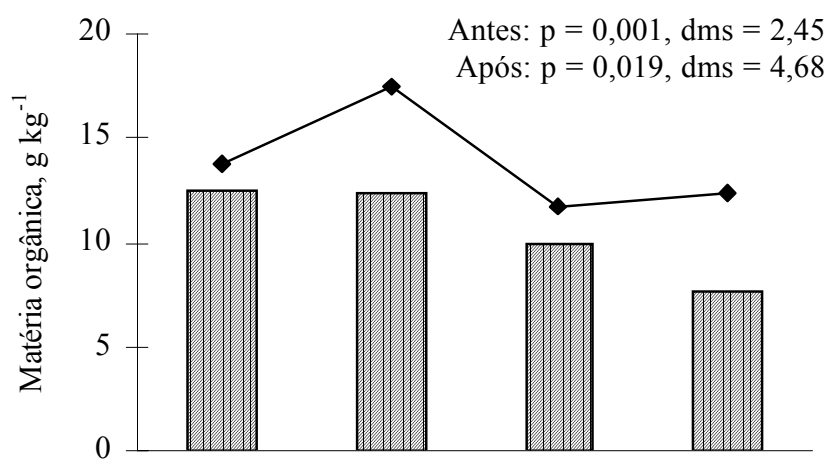

F.

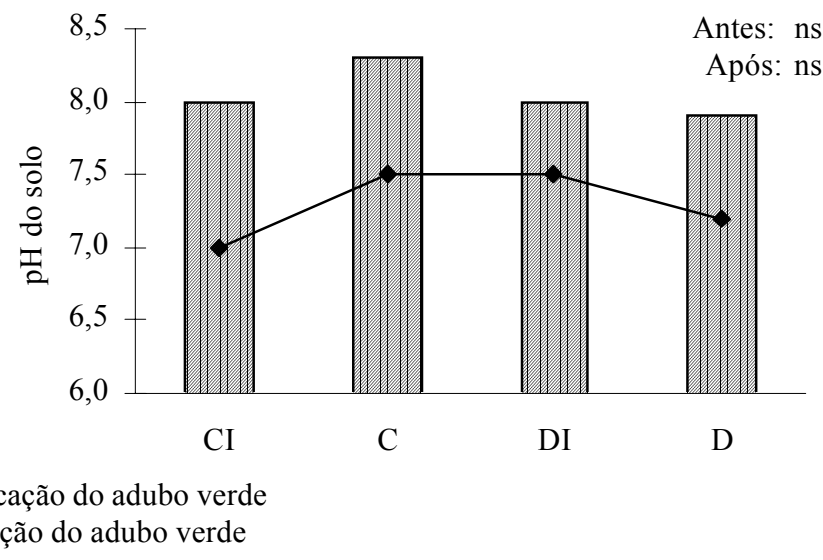

Figura 4. Teores de nitrogênio (A), fósforo $(B)$, potássio $(C)$, magnésio (D), matéria orgânica (E) e pH do solo (F), em um Luvissolo em condições conservadas com inoculação $(\mathrm{Cl})$, sem inoculação $(\mathrm{C})$, degradadas com inoculação (DI) e sem inoculação (D), antes e após a incubação do adubo verde

téria orgânica detectados nos solos erodidos. Os aumentos nos valores dos nutrientes encontrados no solo foram ocasionados pelo acúmulo da matéria orgânica, proporcionado pelo adubo verde e pela rotação de culturas, concordando com Melo Filho (1991); Sá (1993); Oliveira (1994); Paula et al. (1998); Maria et al. (1999) e Silveira \& Stone (2001).

Com relação ao $\mathrm{pH}$, vê-se que a incubação com o feijãode-porco proporcionou, ao pH do solo, redução de 9,6, 12,5, 8,9 e $6,3 \%$ para C, CI, D e DI, respectivamente. Provavelmente, o ácido carbônico proveniente da decomposição da matéria orgânica presente no adubo verde reagiu com carbonatos de $\mathrm{Ca}$ e $\mathrm{Mg}$ do solo, para formar bicarbonatos solúveis que foram lixiviados, deixando o solo menos alcalino, o que explicaria a redução do Mg após a incubação do adubo verde (Instituto da Potassa \& do Fosfato, 1998).

\section{CONCLUSÕES}

1. Os efeitos prejudiciais da erosão e benéficas da conservação do solo, foram evidenciados em todas as propriedades físicas e químicas, particularmente no teor de matéria orgânica.

2. As melhores condições físicas e químicas encontradas no solo conservado potencializaram os efeitos positivos da inoculação com rizóbios, associada à rotação de feijão-deporco com o algodão.

3. No solo degradado a inoculação do rizóbio não conseguiu superar a produção do não inoculado na cultura do algodoeiro sendo, porém, notável, a sua superioridade na cultura do feijão-de-porco.

4. As condições no solo degradado foram melhoradas pela rotação feijão-de-porco/algodão, principalmente em função da leguminosa ter sido usada como adubo verde. 


\section{LITERATURA CITADA}

EMBRAPA - Empresa Brasileira de Pesquisa Agropecuária da Paraíba. Manual de métodos de análise de solo. 2ed. Versão atualizada. Rio de Janeiro: CNPS. 1997. 212p.

EMBRAPA - Empresa Brasileira de Pesquisa Agropecuária da Paraíba. Centro Nacional de Pesquisa de Solos. Sistema brasileiro de classificação de solos. 1F edição. Brasília. Embrapa Produção de Informação. Rio de Janeiro: Embrapa Solos, 1999. 412p.

Instituto da Potassa \& do Fosfatos. Manual internacional de fertilidade do solo. Tradução e adaptação de Alfredo Scheid Lopes. 2.ed. verificada e ampliada Piracicaba: Potafos, 1998. 177p.

Kiehl E.J. Fertilizantes orgânicos. Piracicaba: Editora Agronômica Ceres. 1985. 492p.

Maria, I.C. de.; Nnabude, P.C.; Castro, O.M. de. Long-term tillage and crop rotation effects on soil chemical properties of a Rhodic Ferralsol in southern Brazil. Soil \& Tillage Research, Amsterdam, v.51, n.1, p.71-79, 1999.

Melo Filho, J.F. Comparação dos sistemas de manejo plantio direto e convencional na conservação do solo e água e produtividade da cultura do milho em Podzólico VermelhoAmarelo Eutrófico. Fortaleza: UFC, 1991, 75p. Dissertação Mestrado

Merten, G.H.; Mielniczuk, J. Distribuição do sistema radicular e dos nutrientes em Latossolo Roxo sob dois sistemas de preparo de solo. Revista Brasileira de Ciência do Solo, Campinas, v.15, n.3, p.369-374, 1991.

Oliveira, E.L. de. Coberturas verdes de inverno e adubação nitrogenada em algodoeiro. Revista Brasileira de Ciência do Solo, Campinas, v.18, p.235-241, 1994.
Paula, M.B. de.; De Assis, R.P.; Bahia, V.G.; Oliveira, C.V. de. Efeitos do manejo dos resíduos culturais, adubos verdes, rotação de culturas e aplicação de corretivos nas propriedades físicas e recuperação dos solos. Informe Agropecuário, Belo Horizonte, v.191, p.66-70, 1998.

Pierce, F.J. Erosion productivity impact prediction. In: Lal, R.; Pierce, F.J. ed. Soil managemente for sustainability. Ankeny: Soil and Water Conservation Society. 1991. p.35-52.

Ryan, B.F.; Joiner, B.L.; Ryan Jr., T.A. Minitab Handbook. 2. ed. Boston: PWS-KENT Publishing Company. 1985. 376p.

Sá, J.C. de M. Manejo da fertilidade do solo no sistema plantio direto. In: EMBRAPA. Centro Nacional de Pesquisa de Trigo (Passo Fundo, RS). Plantio direto no Brasil. Passo Fundo: EMBRAPA-CNPT/FUNDACEP-FECOTRIGO/Fundação ABC, 1993. p.37-60.

Santos, H.P. dos.; Siqueira, O.J.W. de. Plantio direto e rotação de culturas para cevada: efeito sobre a fertilidade do solo. Revista Brasileira de Ciência do Solo, Campinas, v.20, n.2, p.163-1169, 1996.

Silveira, P.M.; Stone, L.F. Teores de nutrientes e de matéria orgânica afetados pela rotação de culturas e sistemas de preparo do solo. Revista Brasileira de Ciência do Solo, Viçosa, v.25, n.2, p.387-394, 2001.

Stewart, B.A.; Lal, R.; El-Swaify, S.A. Sustaining the resource base of expanding world agriculture. In: Lal, R.;. Pierce, F.J. (eds.). Soil management for sustainability. Ankeny: Soil and Water Conservation Society. 1991. p.125-144.

Teixeira, C.F.A.; Pauletto, E.A.; Silva, J.B. da. Resistência mecânica à penetração de um Argissolo Amarelo distrófico típico sob diferentes sistemas de produção em plantio direto. Ciência Rural, Santa Maria, v.33, n.6, p.1165-1167, 2003.

van Raij, B. Avaliação da fertilidade do solo. Piracicaba: Instituto da Potassa \& Fosfato: Instituto Internacional da Potassa, 1981. 142p. 